ORIGINAL PAPERS

報 文

(32)

\title{
2 成分系の比揮発度におよほす溶蝺の影響*
}

藤田重交**.小川茂**.渡辺好邦***

要旨 抽出蒸溜に执いては溶㓮の選択が問題となる か，原 2 成分系の比揮哞度を適当に增加させる溶郕をど らして選べばよいか，その目安となるるのはまだわか。 ていないようである。

この報告は分離しにくい2 成分系として $\mathrm{CCl}_{4}-\mathrm{C}_{6} \mathrm{H}_{6}$ 系を選び，これに 4 種の溶刘を加えて，比揮発度の增加 率を実測し，その結果について険討を行ったるのである。

\section{1、実験試料および実験方法}

原系として用いた四塩化炭素およびベンゼンはそれを れおらかじめ実験室用充填塔て蒸溜精製し，溶剤として 用いたフルフラールは减圧蒸溜によって精製したが，他 の 3 種の溶戍，フェノール，フニリン，ニトロベンゼン は市販の試薬特級または最純品をそのまま使用した。

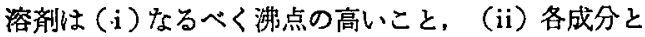
十分に溶解すること，（iii）原系各成分との 2 成分系平 衡関係がなるべく既知であること，の3 条件を考虑して 前記の 4 種を選んだ。これら溶郕の沸点はフルフラー ル,フェノール，アニリン，ートロベンゼンの順にそれ それ，161.7, 181.4, 184.4, $210.9^{\circ} \mathrm{C}$ である。

実験試料としては組成既知の $\mathrm{CCl}_{4}-\mathrm{C}_{6} \mathrm{H}_{6}$ 混合液（大 部分の実験は等モ儿混合液）飞各溶郕の既知量を加えた るのを用い，著者らの1人小川方改良した口ザノフ型平

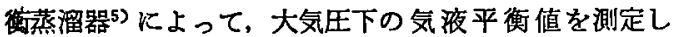
た。周知のようにロザノフ型は画分溜出量々その組成の “等緅から溜出量ゼロに補外したときの組成を原液組成と 平衡な蒸気組成とするすのであるから，分析は溜出液の 之について行えばよい。その分析には別に分析用蒸溜器 によって溶剤のみをあらかじめ分離し（原系と溶郕との 比揮発度は十分大であるから容易に分離可能である)，2 成分混合物々分離した溶剤の量とをはかり，つきに2 成 分混合液の $30^{\circ} \mathrm{C}$ 亿和ける密度を測定してその組成を決 定した。このために必要な組成一密度の関係はあらかし ஆ実测した。Table 1 はその結果である。

\section{2. 実験結果とその整理}

すべての実测値を Table 2 に示した。 $x_{C}=1-x_{A}-x_{B}$,

* 昭和 33 年 5 月 9 日受理

**東京工策大学

*** 興和化学
$y_{C}=1-y_{A}-y_{B}$ であるから, 表中には $x_{C}, y_{C}$ の記暒を省 略した。表中第 5 楖に示した $\alpha_{A B / C}$ は溶剤の存在する場 合の $\mathrm{CCl}_{4}-\mathrm{C}_{6} \mathrm{H}_{6} 2$ 成分の比揮発度で，実測值から $\alpha_{A B / C}$ $=y_{A} \cdot x_{B} / y_{B} \cdot x_{A}$ にっって計算した值である。いうまでる なくこの值は

$$
\alpha_{A B / C}=\left(\frac{y_{A}}{y_{A}+y_{B}}\right)\left(\frac{x_{B}}{x_{A}+x_{B}}\right) /\left(\frac{y_{B}}{y_{A}+y_{B}}\right)\left(\frac{x_{A}}{x_{A}+x_{B}}\right)
$$
のようにも書けるから，いいかえれば $x_{A} /\left(x_{A}+x_{B}\right)$ : $y_{A} /\left(y_{A}+y_{B}\right)$ の点緅による曲楾, すなわち溶郕妨きの平 衡曲線の比揮発度と考えてもよい。したがって， $\alpha_{A B / C}$ 之溶剂を加之ぬ原 2 成分系の比揮発度 $\alpha_{A B}$ とを比較す れば，溶剤添加に上る比揮発度の增加率がわかるわけで ある。しかるに $\mathrm{CCl}_{4}-\mathrm{C}_{6} \mathrm{H}_{6}$ 系の比揮発度 ${ }^{6)}$ は $x_{A}{ }^{\prime}=0.10$ 〜0.73 の範用では近似的に次式であらわされる****。

$$
\alpha_{A B}=1.100\left(\frac{1-x_{A}{ }^{\prime}}{x_{A}^{\prime}}\right)^{0.043}
$$

すなわち， $x_{4}^{\prime}=0.10$ で $\alpha_{A B}=1.209, x_{A}{ }^{\prime}=0.50$ で $\alpha_{A B}$ $=1.100, x_{A}{ }^{\prime}=0.70$ で $\alpha_{A B}=1.061$ の程度に变化する。 このことを知って Table 2 の $\alpha_{A B / C}$ をみれば, 各溶郕と す原系の比揮発度を增加させていることはあきらかであ るが, 直接 $\alpha_{A B / C}$ と $\alpha_{A B}$ とを比較するためには $\alpha_{A B}$ を規 定する組成 $x_{A}{ }^{\prime}$ に対応する 3 成分系の組成として何を採 用するかをきめなければならない。ちょっと考えると溶 剤ぬきの組成 $x_{A} /\left(x_{A}+x_{B}\right)$ を基準にするのが合理的の

Table 1

Density of $\mathrm{CCl}_{4}-\mathrm{C}_{6} \mathrm{H}_{6}$ system at $30^{\circ} \mathrm{C}$

\begin{tabular}{cc} 
Concn. of CCl in liquid \\
\hline (wt. \%) & $($ mol. \%) \\
\hline 0 & 0 \\
10 & 5.5 \\
20 & 11.3 \\
30 & 17.8 \\
40 & 25.2 \\
50 & 33.7 \\
60 & 43.2 \\
70 & 54.4 \\
80 & 67.2 \\
90 & 82.0 \\
100 & 100
\end{tabular}

\begin{tabular}{c} 
Density at $30^{\circ} \mathrm{C}$ \\
\hline$(\mathrm{g} / \mathrm{cc})$ \\
\hline 0.867 \\
0.909 \\
0.952 \\
1.001 \\
1.055 \\
1.117 \\
1.186 \\
1.265 \\
1.354 \\
1.455 \\
1.574
\end{tabular}

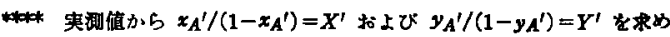
$Y^{\prime}=\alpha^{\prime} X^{n}$ と㨟いて $a^{\prime}, n$ 求めたところ $a^{\prime}=1.100, n=0.957$ を得たので, $\alpha A B=Y^{\prime} / X^{\prime}=1.100 /\left(X^{\prime}\right) 0.043$ となる。 
Table 2 Vapor-liquid equilibria for $\mathrm{CCl}_{4}(\mathrm{~A})-\mathrm{C}_{6} \mathrm{H}_{6}(\mathrm{~B})$-Solvent (C) systems

(a) Solvent: Phenol

\begin{tabular}{cc}
$x_{A}$ & $x_{B}$ \\
\hline 0.100 & 0.100 \\
0.126 & 0.124 \\
0.129 & 0.164 \\
0.150 & 0.150 \\
0.160 & 0.314 \\
0.229 & 0.451 \\
0.350 & 0.350 \\
0.450 & 0.450
\end{tabular}

(b) Solvent: Aniline

(c) Solvent: Nitrobenzene

\begin{tabular}{|c|c|c|c|c|c|}
\hline$x_{A}$ & $x_{B}$ & $y_{A}$ & $y_{B}$ & $a_{A B / C}$ & $x_{A}$ \\
\hline 0.151 & 0.149 & 0.579 & 0.395 & 1.445 & $\begin{array}{l}0.0726 \\
0.075\end{array}$ \\
\hline 0.225 & 0.075 & 0.793 & 0.191 & 1.385 & $\begin{array}{l}0.151 \\
0.174\end{array}$ \\
\hline 0.252 & 0.248 & 0.568 & 0.415 & 1.348 & $\begin{array}{l}0.202 \\
0.224 \\
0.253\end{array}$ \\
\hline 0.353 & 0.347 & 0.564 & 0.434 & 1.278 & 0.353 \\
\hline 0.453 & 0.447 & 0.537 & 0.462 & 1.150 & $\begin{array}{l}0.455 \\
0.523\end{array}$ \\
\hline
\end{tabular}

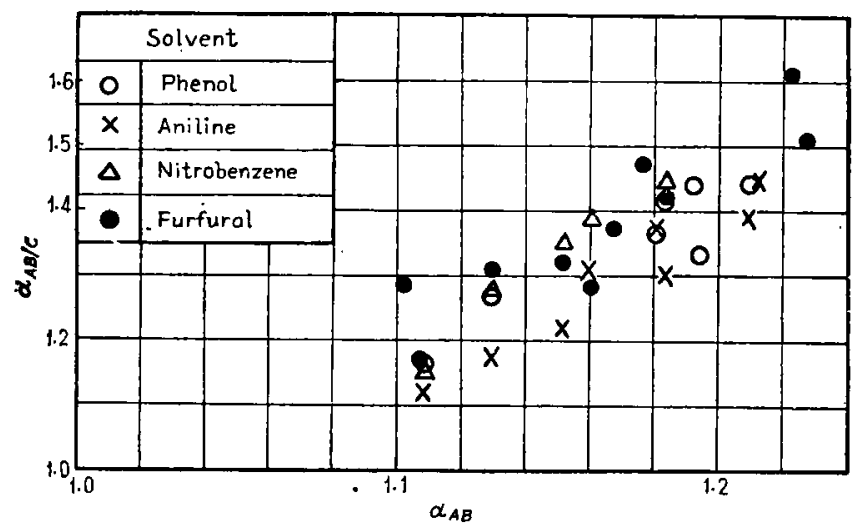

Fig. 1 Comparison of $a_{A B / C}$ and $\epsilon_{A B}$ at $x_{A}=x_{A^{\prime}}$

\begin{tabular}{c}
$x_{A}$ \\
\hline 0.093 \\
0.101 \\
0.151 \\
0.159 \\
0.228 \\
0.253 \\
0.353 \\
0.454
\end{tabular}

\begin{tabular}{c}
$x_{B}$ \\
\hline 0.183 \\
0.099 \\
0.149 \\
0.314 \\
0.449 \\
0.247 \\
0.347 \\
0.446
\end{tabular}

$$
\begin{gathered}
y_{A} \\
\hdashline \mathbf{0 . 4 0 0} \\
0.557 \\
0.555 \\
0.403 \\
0.394 \\
0.543 \\
0.535 \\
0.530
\end{gathered}
$$

(d) Solvent: Furfural

\begin{tabular}{cccc}
$x_{B}$ & $y_{A}$ & $y_{B}$ & $a_{A B I C}$ \\
\hline 0.449 & 0.185 & 0.756 & 1.510 \\
0.225 & 0.306 & 0.571 & 1.610 \\
0.149 & 0.545 & 0.379 & 1.420 \\
0.526 & 0.317 & 0.654 & 1.468 \\
0.198 & & & \\
0.076 & 0.555 & 0.396 & 1.373 \\
0.247 & 0.707 & 0.187 & 1.283 \\
0.347 & 0.524 & 0.387 & 1.320 \\
0.445 & 0.559 & 0.419 & 1.311 \\
0.177 & 0.481 & 0.402 & 1.170 \\
& 0.763 & 0.210 & 1.286
\end{tabular}

異があるとも思えない。すなわち, 溶剂 の種類扣よびその添加量による明確な差： 異は本実験の範囲ではあまりみとめられ ず,むしろ $\alpha_{A B}$ が大きい屝ど $\alpha_{A B / C}$ る大 きいといつ単純な傾向だけがみとめられ： たといらできであろう。しかし、これだ けでは何分にもデータが少なく、かっ， $a_{A B}$ の範围もせまいので，この関係を既 往の文献値について検討してみた。

すなわち，Chu の著書”から nーヘフ タンーメチルシクロヘキサン (以下 $\mathrm{M}$ ・ $\mathrm{C} \cdot \mathrm{H}$ と略す) -トルェン, $\mathrm{M} \cdot \mathrm{C} \cdot \mathrm{H}-$ ト エンーフェノール, $i$ オオタンートルェンー フェノールのデータ艾採用し， $\mathrm{M} \cdot \mathrm{C} \cdot \mathrm{H}-$ トルエンーフ リンについて Fenske ら2)のデータを, また, 非トルェ ンートルェンーフニリン（あるいはフェノール）について。 Perry ${ }^{6)}$ p. 644 のデータを使用して計算した結果を著者 らのデータとともに Fig. 2 に示した。この場合, 溶戍、 を含ま奴成分系の平衡データが必要であるが，n-ヘブ

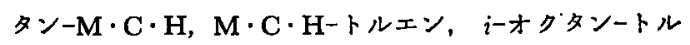
エンについては Chu の著書”のあのを用いた。

Fig. 2 は $\alpha_{A B}: \alpha_{A B / C}$ を対数目盛で点䯅したものであ. り，著者らのデータより既往のデータによる計算值の方 がはるかに多いが、, $\alpha_{A B}$ のかなり広、範囲にわたって著、 者らの点緅法が妥当であることを示している。本図のす ベてのデータを一つの曲線で代表させるにはまた精度が 


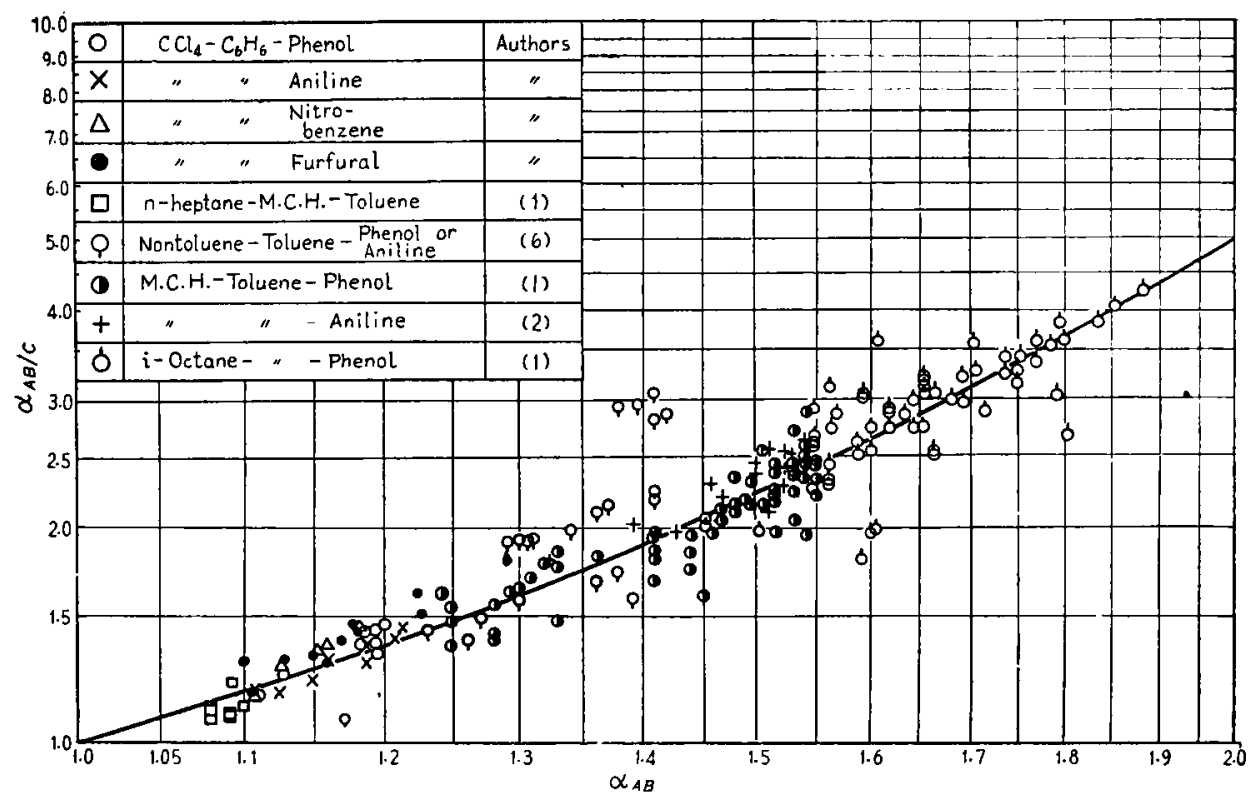

Fig. 2 Comparison of $\alpha_{A B / C}$ and $\alpha_{A B}$ at $x_{A}=x_{A^{\prime}}$



Fig. 3 Comparison of $\alpha_{B C / A}$ and $\alpha_{B C}$ at $x_{C}=x_{C}^{\prime}$

して求めた方がややボラッキが少ないよ うなのでFig.3にその結果を示したが， いずれにしてる近似的に $\alpha_{B C / A} \doteqdot \alpha_{B C}$ と 特けるよ5である。この計算に必要な B-C 2 成分系の平衡值はそれぞれつきの 文献から求めた。ベンゼンーフェノール, ペンゼンーニトロベンゼンについては Martin-George ${ }^{3)}$, ベンゼンーアニリン については Martin-Collie", ベンゼソフルフラールについては Thornton-Garner"), トルェンーフェノールKついては $\mathrm{Chu}^{\mathrm{i}}$ の值を用いたが, トルエンーアニリ ンについてはデータがないのでこの点経 から除いた。

\section{2 成分系の平衡値から 3 成分平衡 値の推定}

この問題は本研究の直接の目的ではな

く，またすでての 3 成分系についてい光 ることではないが，前揭の Fig. 2, Fig.

3 のような関係が成り立つるのとすれ

悪いが，溶剤の種類および添加量による影響については 今後の研究にまちたい。

同様にして $a_{B C / A}(3$ 成分系に和ける $B, C$ 成分の此 揮発度) と $\alpha_{B C}$ との関係についてるしらべた結果, この 場合には $x_{B}=x_{B}{ }^{\prime}$ として $\alpha_{B C}$ を求めるよりも $x_{C}=x_{C}{ }^{\prime}$ と
ば、この両図と A-B 2 成分系および B-C 2 成分系の平 衡関係を知って，A-B-C 3 成分系の平衡関保を計算す ることが可能となるので, その方法を述へておく。

ある液組成 $x_{A}, x_{B}, x_{C}$ k平衡な蒸気組成 $y_{A}, y_{B}, y_{C}$ を 求めるためにはまず，A-B 2 成分系の平衡関係 $\left(\alpha_{A B}\right)$ 

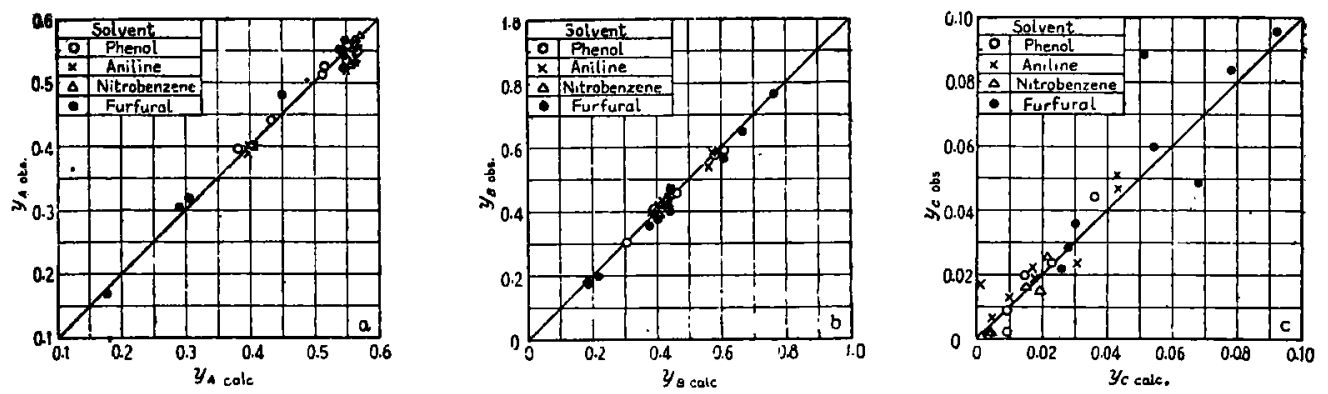

Fig. 4 Comparison of calculated and observed data

と Fig. 2 とから $\alpha_{A B / C} \rightarrow y_{A} / y_{B}$ を求め, 一方 B-C 2 成 分系の平衡関係 $\left(\alpha_{B C}\right)$ と Fig. 3 とから $\alpha_{B C / A} \rightarrow y_{B} / y_{C}$ を求め，この両者から $y_{A} ， y_{B} ， y_{C}$ を求めればよい。たと えば $\mathrm{CCl}_{4} 16.0 \mathrm{~mol} \%, \mathrm{C}_{6} \mathrm{H}_{6} 31.4 \mathrm{~mol} \%$ 、フェノール $54.6 \mathrm{~mol} \%$ の混合液に平衡な蒸気組成はつきのよ 5 に して求められる。 $x_{A}=0.160$ であるから $x_{A}{ }^{\prime}=x_{A}=0.160$ そして $\mathrm{CCl}_{4}-\mathrm{C}_{6} \mathrm{H}_{6}$ 系の平衡関保から $y_{A}{ }^{\prime}=0.183$ が得 られ, $\quad a_{A B}=(0.183)(0.840) /(0.817)(0.160)=1.180$ (あるいは(1) 式から值接に $\alpha_{A B}=1.180$ が得られる)。 よって Fig. 2 の曲線から $\alpha_{A B / C}=1.380$ 。ゆ穴に $y_{A} / y_{B}$ $=\alpha_{A B / C}\left(x_{A} / x_{B}\right)=(1.380)(0.160 / 0.314)=0.703$ 。一方 $\mathrm{C}_{6} \mathrm{H}_{6}-\mathrm{C}_{6} \mathrm{H}_{5} \mathrm{OH}$ の平衡値から $x_{C}=x_{C}{ }^{\prime}=0.546$ に対する $\alpha_{B C}=71.0$ を求め. Fig. 3 の関係から $\alpha_{B C / A}=71.0$ とお いてよいので, $y_{B} / y_{C}=(71.0)(0.314) /(0.546)=40.8$ を 5る。よって, $y_{A}=0.406, y_{B}=0.580, y_{C}=0.014$ が得 られる。この場合の央測値は $y_{A}=0.402, y_{B}=0.578$, $y_{C}=0.020$ で, $y_{A}, y_{B}$ についてはきわめて満足な一致を 示している。

Fig.4はこのような方法で著者らのすべての実測值と 計算值とを比較したものであるが，上例か゚特例でなく， 全般に打いてよい一致を示すことがわかる。

\section{4. 結 論}

この研究は抽出蒸溜に用いる溶剤選択の基準となる目 安を求めるために行ったのであるが，実験結果は意外に も Fig. 2 のよ5な単純なものとなり, 原采の比揮発度が 小さければ溶刜をかえても，その添加量をかえても著し く比揮発度を增加させることは困難のようであることが わかった。るちろん詳細に検討すれば，溶珴の種類によ って多少は異なり，また溶剤量を増せばあきらかに此揮 発度は増加するが, 本実験の範囲では溶凮添加量の增加 が原系の比揮発度をる堌加させる結果になったのであ る。ただしＦig. 2 の点綴に選んだ禾は第 3 成分の沸点
がとくに高いるの，2 相に分離しないるの，共沸点のな いものという条件を満足するるのばかりであって，一般 の 3 成分采については別問題である。したがって，第 3 節で述へた推定法る一般的なるのではないことを付記し て拉く。

\section{Nomenclatures}

$x_{A}, x_{B}, x_{C}:$ Mole fraction of each component in liquid phase of ternary mixtures. Prime refers to binary systems

$y_{A}, y_{B}, y_{C}:$ Mole fraction of each component in vapor phase of ternary mixtures. Prime refers to binary systems

$\alpha_{A B / C}=\frac{y_{A} \cdot x_{B}}{y_{B} \cdot x_{A}}:$ Relative volatility of $A$ and $B$ in ternary mixtures

$\alpha_{B C / A}=\frac{y_{B} \cdot x_{C}}{y_{C} \cdot x_{B}}:$ Relative volatility of $B$ and $C$ in ternary mixtures

$\alpha_{A B}=\frac{y_{A}{ }^{\prime} \cdot x_{B}{ }^{\prime}}{y_{B}{ }^{\prime} \cdot x_{A}{ }^{\prime}}:$ Relative volatility of $A$ and $B$ in binary mixtures

$\alpha_{B C}=\frac{y_{B}{ }^{\prime} \cdot x_{C}{ }^{\prime}}{y_{C}{ }^{\prime} \cdot x_{B}{ }^{\prime}}:$ Relative volatility of $B$ and $C$ in binary mixtures

\section{Literature cited}

1) Chu, J. C. : "Distillation Equilibrium Data," Reinhold Publ. Co. (1950)

2) Fenske, Carlson \& Quiggle : Ind. Eng. Chem., 39, 1322 (1947)

3) Martin \& George : J. Chem. Soc., 1413 (1933)

4) Martin \& Collie : ibid., 2658 (1932)

5) Ogawa, S.: “Kagaku-Kikai.Gijutsu.” No. 6, p. 22 (1954)

6) Perry: " Chemical Engineer's Handbook," 3 rd, ed. (1950)

7) Thornton \& Garner: J. Applied Chem., 1, 561 (1951). 


\title{
Effect of Solvents on the Relative Volatility of Binary Mixtures
}

\author{
S. Fujita, ${ }^{*}$ S. Ogawa* and Y. Watanabe*
}

Using a Rosanoff-type equilibrium still, we tried to determine the ternary equilibria of carbontetrachloride-benzene-solvent systems. The solvents used were phenol, aniline, nitrobenzene and furfural, which were chosen for the four reasons given below:

(1) They have relatively high boiling points.

(2) They are miscible with the original binary mixture.

(3) They do not make an azeotrope.

(4) Equilibrium data in connection with them and each component of the original mixture are available.

All the data obtained and the relative volatility calculated of ternary mixtures, $\alpha_{A B / C}$, are shown in Table 2. The values of $\alpha_{A B / C}$ are compared with the relative volatility of the original binary mixture under the same mole fraction of the most volatile component in the ternary liquid as well as in the binary liquid. The results are shown in Fig. 1, which shows no regularity. A similar graphical representation was given of the data recalculated of those of some previous workers as shown in Fig. 2. From this figure, it may roughly be concluded that over the range of our experiments the larger the relative volatility of the original binary mixtures is, the larger that of the ternary mixtures will be, regardless of the kinds of solvents added. Similar relations were observed between $\alpha_{B C / A}$ and $\alpha_{B C}$, as shown in Fig. 3.

A method for estimating ternary equilibria was obtained from the study of binary equilibria and from the two correlations of Figs. $2 \& 3$. The calculated values of vapor composition were compared with the observed ones as in Fig. 4, which shows a fairly good agreement.

* Tokyo Institute of Technology

(491 ベーシ余白からつつく)

第 5 号 6 月 28 日 New Yorkにて 本日 Philedelphia よりパスで当地に安着致しました。 Philadelphia 滞在中はフメリカ化学工学協会 50 周年記念大会行 事にしたがって行動致しました。まず22日より27日ま てていろいろ講演会があり，また 23 日 25 日には team一 同讣 Du Pont Experimental Station (wilmington) 見 学および 50 周年記念式典 26 日Kは Tidewater の石油 精製工場（Delaware）の見学がありました。請演の中 には，しばしば当 team の一員である八田，藤田先生の 御名が出て意を強くした次第です。式典はヘンンシルパ= ヤ大学でハイプオルガンの演奏のうちにンビェトを含む 20 数力国の学会代表が列席して蕨に施行されました。日 本代表八田団長むガウン着用で坥上に立たれました。 Tidewater の工場は最近完成されたもので最新の石油 精製の各種のブロセスの展覽会場のようで大変興味深く 一同見学しました。なお Du Pont の中央研究所とむい ラペき, Experimental Station は元ゴルフ場の広大なク
リーンを用いた立地で的 1 , 200人の研究員を擁していて， その設诸, 環境全く5らやましい限り。いかに化学工業 が研究を重視しているかを身に治まされた次第でした。 また Philadelphiaはフメりカ独立宣言の古都とて， 美術館，独立記念ホテルその他名所が多く一同能率よく 余叞を活用した次第です。

本 28 日バスにて出発，当 New Yorkに正午頃一同元 気にて安着しました。明日は休み，30日より再び team 行動がはじまります。ではまた。

第6号 7 月6日 ボストンにて 6 月 28 日ニ= ーヨークに着きましたが，翌 29 日は幸い日曜でしたの で一同大いに㲀切って世界一の大都会の観光に終日能率 よく動き回りました。一エンパイヤーステートビル， 国連：ミニジムタイムスクェアー等々一。

30 日は Kellogg Co. 本社を訪ね，午後研究所に行き ました。その中試設備の完䚚しているのと，設計にモデ (以下 507 ベージ余白へつつく) 